\title{
Econometric Models for Computing Safe Withdrawal Rates
}

\author{
Michael D. Prendergast, Ph.D. \\ Colorado Springs, CO, USA \\ michael.david.prendergast@gmail.com
}

\begin{abstract}
This paper describes a methodology for estimating safe withdrawal rates during retirement that is based on a retiree's age, risk tolerance and investment strategy, and then provides results obtained from using that methodology. The estimates are generated by a three-step process. In the first step, Monte Carlo simulations of future inflation rates, 10-year treasury rates, corporate bond rates (AAA and BAA), the S\&P 500 index values and $S \& P 500$ dividend yields are performed. In the second step, portfolio composition and withdrawal rate combinations are evaluated against each of the Monte Carlo simulations in order to calculate portfolio longevity likelihood tables, which are tables that show the likelihood that a portfolio will survive a certain number of years for a given withdrawal rate. In the third and final step, portfolio longevity tables are compared with standard mortality tables in order to estimate the likelihood that the portfolio outlasts the retiree. This three-step approach was then applied using both a Monte Carlo random walk model and an ARIMA/GARCH model based upon over 100 years of monthly historical data. The end result was estimates of the likelihood of portfolio survival to mortality for over 500,000 retiree age/sex/portfolio/withdrawal rate combinations, each combination supported by at least 10,000 Monte Carlo economic simulation points per model. Both models are supported by 100 years of historical data. The first model is a random walk with step sizes determined by bootstrapping, and the second is an ARIMA/GARCH regression model. This data is analyzed to predict safe withdrawal rates and portfolio composition strategies appropriate for the late 2021 economic environment.
\end{abstract}

Keywords - four percent rule, modeling, economics, stock market, interest rate, unemployment, Monte Carlo, simulation, inflation, $S \& P$, bonds, treasuries, retirement.

\section{INTRODUCTION}

\subsection{Background and Prior Work}

The four percent rule is a financial planning rule of thumb that states that a new retiree can safely withdraw four percent of his portfolio during the first year of retirement and continue to withdraw that same amount, indexed for inflation, for the rest of his lifetime without exhausting his portfolio. First proposed by Bill Bengen $[1,2,3]$, the rule has become widely adopted by laypeople and financial advisors alike because it is easy to understand and appears to work well.

Bengen assumed a model portfolio of $50 \%$ bonds and $50 \%$ stocks. His analysis showed that such a portfolio would almost always last at least 30 years if a retiree maintained that portfolio mix through rebalancing and followed the four percent rule.

A plethora of magazine articles and technical papers have since followed. Is $4 \%$ too much (see $[4,5,6,7])$ ? Too little (see
[8])? Does it apply to foreign stock exchanges as well (see [9, 10])? Does it apply to Financial Independence - Retire Early (FIRE) retirees (see [11])? Can returns be enhanced by dynamic withdrawal rates, or "glide paths" (see $[2,11,12]$ ?

Many of the technical papers written on these topics have made use of computer simulations to estimate the likelihood of portfolio depletion, with simulation data obtained through either sampling with replacement of historical data (known as bootstrapping) or, following Bengen's lead in [1], by analysis of historical bond yield and market return data.

These approaches have limitations. First, the use of absolute market returns in bootstrapping instead of using the period-toperiod changes in those indices is problematic. The 10 -year treasury yield mean over the last 100 years has been $4.51 \%$. But at the time of this writing (late 2021) the yield stands at roughly $1.5 \%$. Is a model that predicts an average of $4.51 \%$ for treasury yields next year justifiable? Second, as the investor's adage goes, "past performance may not be indicative of future results". What worked in one market environment may not work in another.

Two techniques to address these issues are a) bootstrapping using logarithmic differences and b) regression. With bootstrapping from logarithmic differences, economic indicators follow a random walk with walk step sizes that follow the historical distribution of walk step sizes. If the historical data exhibits skewness and kurtosis, so will the random walk simulation.

The second method, regression, uses trends to attempt to predict future indicator values. Popular linear regression approaches that employ previous values to forecast future indicator values (with uncertainty) are Autoregression (AR), moving average (MA) and autoregression with moving average (ARMA). The general ARMA(p, q) model is given by (1).

$$
y_{t}=\sum_{k=1}^{p} a_{k} y_{t-p}+\sum_{j=1}^{q} \frac{y_{t-j}}{q}+\varepsilon_{t}
$$

ARIMA models are ARMA models applied to period-toperiod differences or logarithmic differences in indicator values.

Residuals that do not have constant variance are called heteroscedastic, and residuals that depend upon previous residual values $\varepsilon_{t-k}$ are said to be conditionally heteroscedastic. Robert Engle [13] formulated a linear regression approach for estimating the residual variances in AR models when the residuals are conditionally heteroscedastic, a 
technique called the Autoregression Conditional Heteroscedasticity (ARCH) algorithm is used. The ARCH approach was specifically mentioned in the announcement of his being awarded Nobel Prize in Economics in 2003 [14]. The ARCH approach was generalized in 1986 by Bollerslev [15] to include autoregressive moving average (ARMA) models and is called generalized ARCH, or GARCH.

When the residuals are conditionally heteroscedastic, the residual variances for $\mathrm{AR}$ models are approximated in $\mathrm{ARCH}$ by:

$$
\varepsilon_{t}^{2} \approx \sum_{k=1}^{p} c_{k} \varepsilon_{t-k}^{2}
$$

They are approximated in GARCH by:

$$
\sigma_{t}^{2} \approx \sum_{k=1}^{p} c_{k} \varepsilon_{t-k}^{2}+\sum_{k=1}^{q} d_{k} \sigma_{t-k}^{2}
$$

The parameters $c_{k}$ and $d_{k}$ are usually estimated by linear regression.

\subsection{Paper Overview}

This paper describes how safe withdrawal rate estimates can be computed from Monte Carlo simulations of two stochastic economic models, and then applies this technique to compute portfolio survival likelihoods for each model. The first model was a random walk with step size determined by bootstrapping from logarithmic changes in historical data. The second model was an ARMA/GARCH regression model. Both models were constructed from 100 years historical records of changes in corporate and treasury bond yields, consumer price indices, S\&P 500 indices and S\&P 500 dividend yields. A total of 10,000 simulations were generated for each model.

Next, over 3,000 portfolio strategy-withdrawal rate combinations were each evaluated against each simulation. Aggregating these results provided portfolio longevity tables for various portfolio composition and withdrawal rate strategy combinations.

Finally, these portfolio longevity estimates were compared with standard mortality tables to provide the likelihood, by retirement age and sex, that a particular portfolio strategy would survive to mortality.

In total, over 500,000 portfolio longevity estimates were computed for each model, each estimate supported by 10,000 Monte Carlo simulations. The longevity estimates are selectable by sex, retirement age, portfolio composition and initial withdrawal rate.

As expected, the safe retirement rate varies significantly by age, sex and investment strategy. For example, younger retirees had lower safe withdrawal rates than older retirees, and women have lower safe withdrawal rates than men.

Less intuitively, today's low interest rate and high inflation rate environment means that bonds are less safe now than they have been in the past. Indeed, many of the "safest" portfolios in today's environment have high levels of stock and low levels of corporate and treasury bonds. This is because with interest rates low and inflation high, investors who keep their money in these products are losing money on an inflation-adjusted basis.

Section 2 describes the data sources used in this study, and how they were prepared and transformed for the two models. The details of the two econometric models used in this study are described in Section 3. The application of the econometric simulation runs to compute portfolio longevity estimates is described in Section 4. These longevity estimates are then compared with standard mortality tables to compute likelihood estimates of portfolio survival to mortality, which is described in Section 5. The end result is a collection of likelihood estimates for portfolio survival to mortality, each estimate representing a unique retiree age/sex/investment strategy/initial withdrawal rate combination. The ways in which these tables can be used is described in Section 6. Section 6 also includes safe return rate analyses for retirees in various circumstances. Section 7 provides conclusions and suggestions for further research.

\section{DATA SOURCES AND DATA PREPROCESSING}

Monthly S\&P 500 stock prices for the last 101 years (September 1920 to August 2021) were obtained from [16]. This data was transformed into monthly log-return form by:

$$
\Delta S t o c k_{t}=\log \left(S \& P_{t}\right)-\log \left(S \& P_{t-1}\right)
$$

The consumer price index for the last 101 years was also obtained from [16]. The monthly change in inflation was also computed as the month-to-month difference in the logarithm of the index value.

$$
\Delta C P I_{t}=\log \left(C P I_{t}\right)-\log \left(C P I_{t-1}\right)
$$

Moody's bond yields are indices of AAA-rated and BAArated corporate bonds with maturities of at least 20 years. Monthly averages of Moody's corporate bonds going back 101 years was obtained from $[17,18]$. The monthly log-change in these rates were computed in the same manner:

$$
\begin{aligned}
& \Delta{\text { AA } \text { Arate }_{t}}=\log \left(\text { AAArate }_{t}\right)-\log \left(\text { AAArate }_{t-1}\right), \\
& \Delta \text { AAArate }_{t}=\log \left(\text { BAArate }_{t}\right)-\log \left(\text { BAArate }_{t-1}\right) .
\end{aligned}
$$

The United States 10-Year Treasury notes were obtained from [19], and the logarithm of the differences in monthly rates for these were also computed.

Note that the logarithm transformation of interest rate data precludes the interest rate from being negative. This makes perfect sense for corporate yields; nobody would invest in a company that promised to take money from their pocket. Whereas there has been some speculation that Treasury interest rates may be negative at some point in the future, but doing so would be against Federal Reserve policy [20].

S\&P 500 dividend yields were obtained from [16] and also are transformed by taking the difference of the natural logarithm of the dividend rates. Just as with interest rates, this precludes dividends yields from turning negative.

\section{MODELING APPROACHES}

The first step in the three-step approach to estimating safe withdrawal rates is to make stochastic economic predictions into the future. Two modeling approaches were used for this effort. The first approach, described in Section 3.1, is a random walk with variable step size. Step sizes are chosen by random selection with replacement of previous step sizes from the historical dataset, a process known as bootstrapping. The 
second approach, described in Section 3.2, is an ARIMA/GARCH regression of the transformed dataset. These approaches are described in the subsections that follow.

\subsection{Random Walk Method}

We start with an initial (current) consumer price index of $C P I_{o}$, an initial S\&P 500 stock index and dividend yield of Stock $_{0}$ and Div $_{0}$, and initial AAA, BAA and 10-year US treasury rates of $A A A_{0}, B A A_{o}$ and $T e n Y r_{0}$. From the transformations described in the previous section, our dataset consists of 100 years of monthly historical logarithm difference tuples, $\left(\Delta C P I_{t}, \Delta\right.$ Stock $_{t}, \Delta A A A_{t}, \Delta B A A_{t}, \Delta \operatorname{TenYr}_{t}$, $\left.\Delta D i v_{t}\right)$. Using 100 years of monthly historical data, the indices $t$ are integers in the interval [-1199,0].

For each step of the random walk, randomly select $t$ ' with replacement from this set of integers and use it to predict the economic indicators in the next month, using the formulas:

$$
\begin{gathered}
C P I_{t+1}=C P I_{t} * e^{\Delta C P I_{t^{\prime}}}, \\
\operatorname{Stock}_{t+1}=\operatorname{Stock}_{t} * e^{\Delta S t o c k_{t^{\prime}}}, \\
\operatorname{Div}_{t+1}=\operatorname{Div}_{t} * e^{\Delta D i v_{t^{\prime}}}, \\
A A A_{t+1}=A A A_{t} * e^{\Delta A A A_{t^{\prime}}}, \\
B B B_{t+1}=B B B_{t} * e^{\Delta B B B_{t^{\prime}}} \text { and } \\
\operatorname{TenYr}_{t+1}=\operatorname{TenYr}_{t} e^{\Delta \operatorname{TenYr}_{t^{\prime}}} .
\end{gathered}
$$

To perform a random walk 100 years into the future, repeat this process 1200 times.

\subsection{ARIMA-GARCH Method}

ARIMA model fits were attempted for each of the 100-year data sets: $\triangle C P I_{t}, \Delta$ Stock $_{t}, \Delta D_{i v}, \Delta A A A_{t}, \Delta B A A_{t}$ and $\Delta$ TenYr $_{t}$. Regression residual variances were then computed and estimated using GARCH regression. The residual $\varepsilon_{t}$ is then randomly selected from a normal distribution based upon its expected variance as computed by the GARCH model.

For both ARIMA and GARCH, only statistically significant variables in the model were retained, significance being determined by p-statistic of 0.15 or less. Predicted R-squared was used to guard against overfitting. Model variables were pruned whenever predicted R-squared differed from adjusted $\mathrm{R}$-squared by more than 0.05 and the pruning resulted in an increase in predicted R-squared.

Details for each of the so derived sub-models are described in the sub sections below.

\subsubsection{Inflation Model}

Equation (8) shows the ARIMA/GARCH inflation model.

$$
\begin{aligned}
\Delta C P I_{t+1}= & 0.00053+0.27 \Delta C P I_{t}+0.050 \Delta C P I_{t-1}+0.47 \Delta C P I_{\text {avg }} \\
& (0.00075)(6.0 \mathrm{E}-18) \quad(0.11)
\end{aligned}
$$

$\sigma_{t+1}^{2} \approx 0.00027$

Parenthetical numbers below the model coefficients denote the $p$-value of that coefficient. The best fit model included two lags and a one-year moving average. The model includes a small core "natural" inflation rate of

$$
e^{12 * .00053 /(1-.27-.05-.47)}-1=3.09 \% .
$$

No statistically significant GARCH model was found for CPI. Hence, inflation variance was modeled as a constant based upon the historical data. The R-squared of the variance of this data is provided in Table 1 below.

Table 1: Inflation Model Fit
\begin{tabular}{|c|c|c|c|}
\hline & R-Squared & Adjusted R2 & Predicted R2 \\
\hline ARIMA & 0.2800 & 0.2782 & 0.2703 \\
\hline GARCH & N/A & N/A & N/A \\
\hline
\end{tabular}

\subsubsection{S\&P 500 Stock and Dividend Models}

The ARIMA-GARCH model for stock price changes are shown in Equation (9).

$$
\begin{gathered}
\Delta S t k_{t+1}=0.0036+0.28 \Delta S t k_{t}-0.010 \Delta S t k_{t-1} \\
(0.00478)(2.03 \mathrm{E}-19) \quad(0.001319) \\
-0.063 \Delta S t k_{t-2}+0.22 \Delta S t k_{\text {avg }}+\varepsilon_{t+1} \\
(0.040) \quad(.013) \\
\sigma_{t+1}^{2} \approx 0.000275+0.26 \varepsilon_{t}^{2}+.47 \sigma_{t}^{2}+.078 \sigma_{t-5}^{2} \\
(0.0076)(8.6 \mathrm{E}-67)(1.6 \mathrm{E}-85)(.000375)
\end{gathered}
$$

The moving average is computed over a one-year timeframe. The modeled long-term growth rate of stocks is derived from this regression as:

$$
e^{12 *(.0036 /(1-.28+.1+.063-.22)}-1=6.7 \%,
$$

excluding dividends. The positive coefficient for moving average implies that stocks trending upward continue to trend upward. There is a small reversion to the mean effect in the second and third lags.

All of the GARCH residual model components are highly significant. The long-term monthly variance in the log of the stock index price change tends toward

$$
.000275 /(1.0-0.26-0.47-.078)=0.00143 \text {, }
$$

from which the index "core" standard deviation is approximated by:

$$
\text { Index Standard Deviation }=e^{\sqrt{12 * .00143}}-1,
$$

or about $14 \%$.

Table 2 shows the model fit in terms of capturing residual errors. We see that although the ARIMA parameters were very significant, the model fit was poor, with a predicted R-squared of only 0.07 . This shows that, though the trend is real, there is still considerable variability in stock prices that are not captured in historical data. The GARCH residual model however had a much better model fit with a predicted R-squared of 0.51 .

Table 2: Stock Price Model Fit

\begin{tabular}{|c|c|c|c|}
\hline & R-Squared & Adjusted R2 & Predicted R2 \\
\hline ARIMA & 0.0911 & 0.0880 & 0.0712 \\
\hline GARCH & 0.5555 & 0.5543 & 0.5053 \\
\hline
\end{tabular}

The dividend yield model is shown in equation (10) below.

$$
\begin{aligned}
\Delta D_{i v_{t+1}}= & 0.37 \Delta D i v_{t}-0.17 \Delta D i v_{t-1}+\varepsilon_{t+1} \\
& (9.8 \mathrm{E}-37)(1.38 \mathrm{E}-09) \\
\sigma_{t+1}^{2} \approx & 5.7 E-06
\end{aligned}
$$

The dividend model fit was $\mathrm{AR}(2)$. The two lagged parameters were very statistically significant, but explained a 
relatively small percentage of the residual sum of squares. No statistically significant moving average contribution to the model was found.

No statistically significant GARCH model for dividend yield was discovered either. In its place, dividend yield variance was modeled as a constant based upon the historical dividend yield changes.

Table 3 depicts the fit for the AR(2) and GARCH dividend yield models.

Table 3: Dividend Model Fit
\begin{tabular}{|c|c|c|c|}
\hline & R-Squared & Adjusted R2 & Predicted R2 \\
\hline ARIMA & 0.128 & 0.1264 & 0.0913 \\
\hline GARCH & N/A & N/A & N/A \\
\hline
\end{tabular}

\subsubsection{0-Year Treasury Note Yield Model}

The Ten-Year treasury yield data were successfully fit to an $\operatorname{ARIMA}(3,1,24)$ model and the resulting residuals were fit to a GARCH $(1,2)$ model, which is shown in Equation (11).

$$
\begin{gathered}
\Delta \text { TenY }_{t+1}=0.39 \Delta \text { TenYr }_{t}-0.22 \Delta \text { TenYr }_{t-1} \\
(2.63 \mathrm{E}-38)(6.57 \mathrm{E}-13) \\
+.085 \Delta \text { TenYr } r_{t-2}-0.26 \Delta \text { TenYr } r_{a v g}+\varepsilon_{t+1} \\
(0.0036)(0.115) \\
\sigma_{t+1}^{2} \approx 5.7 \mathrm{E}-7+0.39 \varepsilon_{t}^{2}-0.12 \varepsilon_{t-1}^{2}+.50 \sigma_{t}^{2} \\
(0.0013)(1 \mathrm{E}-148)(2.2 \mathrm{E}-11)(1.4 \mathrm{E}-66)
\end{gathered}
$$

All of the parameters were extremely significant except for the 24-month moving average component, which had a p-value of 0.115 but was still below the cutoff threshold of $p=0.15$.

The yield intercept in the model was not statistically significant, so set to zero. This is equivalent to stating that the $\log$ of 10-year treasury yields have an equally likely chance of going up or down in the next period if they are unchanged in the current period and recent history. To put it another way, interest rates that have been low and unchanging for a long period of time are likely to stay low in the near term, and interest rates that have been high and unchanging for a long period are likely to stay high; there is no mean-reversion effect.

Table 4: T-Note Yield Model Fit

\begin{tabular}{|c|c|c|c|}
\hline & R-Squared & Adjusted R2 & Predicted R2 \\
\hline ARIMA & 0.1372 & 0.1342 & 0.1151 \\
\hline GARCH & 0.6661 & 0.6652 & 0.6169 \\
\hline
\end{tabular}

\subsubsection{Corporate Bond Yield Models}

The ARIMA and ARCH models for corporate AAA bonds are shown in equation (12) below.

$$
\begin{gathered}
\Delta A A A_{t+1}=0.38 \Delta A A A_{t}-0.19 \Delta A A A_{t-1}+\varepsilon_{t+1} \\
(1.7 \mathrm{E}-37) \quad(2.8 \mathrm{E}-11) \\
\varepsilon_{t+1}^{2} \approx 1.05 \mathrm{E}-7+0.17 \varepsilon_{t}^{2}+.37 \varepsilon_{t-1}^{2} \\
(1 \mathrm{E}-7)(3.1 \mathrm{E}-10)(1.8 \mathrm{E}-40)
\end{gathered}
$$

The ARIMA model of Moody's AAA bond yields had no statistically significant intercept component, so it also had no mean-reversion effect built into it. No statistically significant moving average component was found for it either. Hence the resulting model was an $\mathrm{AR}(2)$. The statistical significance of the two lagged variables in the model was very high, however, and the corresponding $\mathrm{p}$-values were very low.
The significance of the ARCH model was also extremely high. Model fit was relatively poor, however (Table 5), indicating that there were other factors missing from the model that also contribute to bond yield volatility.

Table 5: AAA Yield Model Fit
\begin{tabular}{|c|c|c|c|}
\hline & R-Squared & Adjusted R2 & Predicted R2 \\
\hline ARMA & 0.1323 & 0.1308 & 0.1192 \\
\hline GARCH & 0.2011 & 0.1997 & 0.1605 \\
\hline
\end{tabular}

The BAA bond yield was fit to an $\operatorname{ARIMA}(2,1,12)$ model. It was similar to the AAA bond yield model, but the BAA model included a statistically significant 12 -montth moving average component with a p-value of 0.098 . Several of the moving average components (at lags 1, 7 and 11) contributed significantly to the GARCH model.

$$
\begin{gathered}
\Delta B A A_{t+1}=0.27 \Delta B A A_{t}-0.17 \Delta B A A_{t-2}+0.29 \Delta B A A_{\text {avg }}+\varepsilon_{t+1} \\
(1.1 \mathrm{E}-19) \quad(0.115) \\
\sigma_{t+1}^{2} \approx 4.4 \mathrm{E}-7+0.23 \varepsilon_{t}^{2}+0.38 \sigma_{t}^{2}+0.29 \sigma_{t-6}^{2}-0.10 \sigma_{t-10}^{2} \\
(0.074)(5.8 \mathrm{E}-59)(9.8 \mathrm{E}-56)(4.3 \mathrm{E}-42)(2.7 \mathrm{E}-07)
\end{gathered}
$$

As seen in Table 6, the GARCH model had a good variance fit, with an adjusted R-squared of 0.60 and predicted R-squared of 0.52 .

Table 6: BAA Yield Model Fit
\begin{tabular}{|c|c|c|c|}
\hline & R-Squared & Adjusted R2 & Predicted R2 \\
\hline ARMA & 0.1178 & 0.1155 & 0.0977 \\
\hline GARCH & 0.6006 & 0.5992 & 0.5186 \\
\hline
\end{tabular}

\section{ESTIMATING PORTFOLIO LONGEVITY}

The second step of the three steps used to determine safe withdrawal rates was to estimate portfolio longevity for a given investment mix and withdrawal rate.

Investor portfolios consisted of a mix of the S\&P 500 index, 10-year US treasuries, AAA-rated corporate bonds and BAArated corporate bonds. Each investment options could be specified in multiples of $10 \%$. For example, an investor can select a portfolio consisting of 50\% S\&P 500 stocks, 20\% 10year US treasuries, $20 \%$ AAA corporate bonds, and 10\% BAA corporate bonds. There are 286 such investment combinations.

We designate $S, T, A$ and $B$ to be the percentage allocations for stocks, US treasuries, AAA bonds and BAA bonds, respectively, and note that

$$
S+T+A+B=1 .
$$

We assume rebalancing at the end of each month.

Initial withdrawal strategies were permitted to range from $1 \%$ to $6 \%$ in intervals of $0.5 \%$ (11 values in total). After the initial withdrawal, future withdrawal levels were indexed to inflation.

The initial portfolio value was set to $\$ 1,000,000$ for each of the simulation runs, and then future portfolio values were iteratively computed according to the following formula:

$P_{t+1}=P_{t} *\left(1+\Delta S_{t+1}+\Delta T_{t+1}+\Delta A_{t+1}+\Delta B_{t+1}\right)-W_{t+1}$

where the $\Delta S_{t+1}, \Delta T_{t+1}, \Delta A_{t+1}, \Delta B_{t+1}$ represent the monthly growth of the respective asset classes, and $W_{t+1}$ is the absolute asset withdrawal amount for the current period.

How each of these individual components were computed is described below. 


\subsection{Portfolio Growth from Stock Investments}

The growth in stock investments $\Delta S_{t+1}$ comes from two sources: dividends and price appreciation. By assuming that dividends are distributed uniformly throughout the year, this becomes:

$$
\Delta S_{t+1}=S\left(\frac{\text { Dividend }_{t}}{12}+\frac{\text { Stock }_{t+1}}{\text { Stock }_{t}}\right),
$$

which is the portfolio growth due to dividends and price appreciation for the proportion of the portfolio allocated to stocks.

\subsection{Portfolio Growth due to Treasury Investments}

Similarly, the growth in portfolio due to treasury investments also has two components, one due to interest rate payments and the other due to capital gains (or losses) due to falling (or rising) interest rates:

$$
\Delta T_{t+1}=\Delta \text { Tcapgains }_{t+1}+\Delta \text { Tinterest }_{t+1}
$$

Interest on 10-year treasury notes is paid semi-annually, but we will assume that the portfolio contains a mix of due dates so that the interest payments are uniform throughout the year. Hence the interest yield per month is given by

$$
\Delta \text { Tinterest }_{t+1}=T\left(\frac{\text { TenYr }_{t}}{12}\right) \text {. }
$$

To compute the capital gain from treasury interest rate changes, note that the percentage capital gain is equivalent to the change in value of a $\$ 1$ treasury that had an old interest rate of $\mathrm{TenYr}_{t}$ at time $t$ but now have an interest rate of TenYr $r_{t+1}$. To compute the new value of this treasury, both the periodic interest payments and the final principal payment must be considered. We assume that the interest payments are paid out monthly (an assumption that is not strictly speaking true but suitable for an approximation) and that the $\$ 1$ principal is paid out in 10 years. Hence the total capital gains for this scenario are approximately given by:

$$
\begin{aligned}
& \Delta \text { Tcapgain }_{t+1}= \\
& \qquad \frac{T}{\left(1+\text { TenYr }_{t+1}\right)^{10}}+T \sum_{i=1}^{120} \frac{\left(1+\text { TenYr }_{t}\right)^{\frac{1}{12}}-1}{\left(1+T e n Y r_{t+1}\right)^{\frac{i}{12}}}
\end{aligned}
$$

which can be approximated as

$$
\frac{T}{\left(1+T e n Y r_{t+1}\right)^{10}}+T \sum_{i=1}^{120} \frac{\operatorname{TenYr}_{t} / 12}{\left(1+\operatorname{TenY}_{t+1}\right)^{\frac{i}{12}}}
$$

Combining (17) and (18), the percentage increase in 10-Year Treasury Note portfolio value from one period to the next is approximately:

$$
\begin{aligned}
\Delta T_{t+1}= & T \frac{\operatorname{TenY}_{t}}{12}+\frac{T}{\left(1+T e n Y r_{t+1}\right)^{10}} \\
& +T \sum_{i=1}^{120} \frac{T e n Y r_{t} / 12}{\left(1+T e n Y r_{t+1}\right)^{\frac{i}{12}}}
\end{aligned}
$$

\subsection{Portfolio Growth due to Corporate Bond Investments}

Just as with US treasuries, portfolio growth due to corporate bonds is the result of two factors: interest rate changes and capital gains (or losses) due to the change in the discounted value of the underlying bonds.
In a manner similar to computing the change in portfolio due to Treasury yield changes, we have

$$
\begin{aligned}
\Delta A_{t+1}=A \frac{A A A_{t}}{12}+A \frac{1}{\left(1+A A A_{t+1}\right)^{20}} & \\
& +A \sum_{i=1}^{240} \frac{A A A_{t} / 12}{\left(1+A A A_{t+1}\right)^{\frac{i}{12}}}
\end{aligned}
$$

and

$$
\begin{aligned}
\Delta B_{t+1}=B \frac{B A A_{t}}{12} & +B \frac{1}{\left(1+B A A_{t+1}\right)^{20}} \\
& +B \sum_{i=1}^{240} \frac{B A A_{t} / 12}{\left(1+B A A_{t+1}\right)^{\frac{i}{12}}}
\end{aligned}
$$

\subsection{Portfolio Shrinkage due to Withdrawals}

The initial monthly withdrawal $W_{0}$ is $1 / 12$ of the are initial yearly withdrawal percentage from the entire portfolio. This withdrawal amount is then regularly adjusted in step with the consumer price index:

$$
W_{t+1}=\frac{W_{t} * C I_{t+1}}{C P I_{t}} .
$$

\subsection{Evaluating Portfolio Longevity}

A total of 286 portfolio composition combinations were evaluated, each with 11 different withdrawal rate assumptions, for a total of $286 * 11=3,146$ portfolio strategies. Each of these strategies was evaluated against each of the 10,000 economic scenarios for each of the two econometric models (random walk and ARIMA/GARCH). For each scenario/portfolio combination, the number of months that the portfolio lasted before depletion is recorded. Scenario/portfolio combinations that survive more than 100 years are set to 100 years (1200 months) duration.

\section{COMPUting SAFE WithdRAWAL RATES AND OPtimaL PORTFOLIOS}

The portfolio longevity estimates from the previous section were used to estimate the likelihood that a portfolio/strategy combination will exceed a given number of months. The standard mortality tables [21] provide, by sex and age, the likelihood that an individual dies in the next year. From these two sets of statistics, one can estimate the likelihood that the portfolio exceeds the retiree's lifespan by summing, for each retiree mortality age, the likelihood that the retiree dies at that age and the portfolio has not been depleted:

$p($ portfolio survival $)=p($ portfolio lifespan $\geq$ retiree lifespan $)$

$=\sum_{n} p$ (portfolio lifespan $\geq n \mid$ retiree lifespan $=n$ ).

These calculations are performed for both male and female retirees for all retirement ages from 20 to 100 , inclusive. For married couples, the couple's lifespan is used in the place of the retiree lifespan in equation (24):

$$
\begin{aligned}
& p(\text { joint mortality at age }=n) \\
& \quad=p(\text { retiree dies at age }=n \text { AND spouse dies at age } \leq n)
\end{aligned}
$$


$+p$ (retiree dies before age $n$ AND spouse dies at age $n)$.

The likelihood of portfolio depletion before mortality is the complement of the likelihood of portfolio survival:

$p($ portfolio depletion $)=1.0-p($ portfolio survival $)$.

Altogether, with 286 investment mixes, 81 retirement ages, 2 sexes and 11 withdrawal strategies there were 509,652 portfolio depletion probabilities for each model, each probability supported by 10,000 separate Monte Carlo simulations. Sample excerpts of portfolio longevity tables, one for the random walk model and one for the ARIMA/GARCH model, are provided in Tables 7 and 8. Table 7 shows some of the probability of portfolio depletion for a female retiree with a $50 \%$ treasury, $50 \%$ stock mix and a $3.5 \%$ initial annual withdrawal rate at various ages. Table 8 shows the likelihood of portfolio depletion for the same strategy using the ARIMA/GARCH model.

Table 7: Random Walk, 50\% stock/treasury, 3.5\% Withdrawal

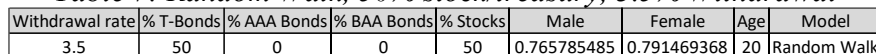
\begin{tabular}{|c|c|c|c|c|c|c|c|c|}
\hline 3.5 & 50 & 0 & 0 & 50 & 0.765785485 & 0.791469368 & 20 & Random Walk \\
\hline 3.5 & 50 & 0 & 0 & 50 & 0.65484293 & 0.689442009 & 30 & Random Walk \\
\hline 3.5 & 50 & 0 & 0 & 50 & 0.485381268 & 0.531539108 & 40 & Random Walk \\
\hline 3.5 & 50 & 0 & 0 & 50 & 0.271382632 & 0.323590678 & 50 & Random Walk \\
\hline 3.5 & 50 & 0 & 0 & 50 & 0.088078331 & 0.123545333 & 60 & Random Walk \\
\hline 3.5 & 50 & 0 & 0 & 50 & 0.075267175 & 0.107859471 & 61 & Random Walk \\
\hline 3.5 & 50 & 0 & 0 & 50 & 0.063678865 & 0.093312227 & 62 & Random Walk \\
\hline 3.5 & 50 & 0 & 0 & 50 & 0.05329855 & 0.079951773 & 63 & Random Walk \\
\hline 3.5 & 50 & 0 & 0 & 50 & 0.044115455 & 0.067815544 & 64 & Random Walk \\
\hline 3.5 & 50 & 0 & 0 & 50 & 0.036079632 & 0.056910717 & 65 & Random Walk \\
\hline
\end{tabular}

Table 8: ARIMA/GARCH, 50\% stock/treasury, 3.5\% Withdrawal

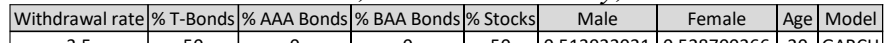
\begin{tabular}{|c|c|c|c|c|c|c|c|c|}
\hline 3.5 & 50 & 0 & 0 & 50 & 0.513922021 & 0.528700266 & 20 & GARCH \\
\hline 3.5 & 50 & 0 & 0 & 50 & 0.457634466 & 0.475801579 & 30 & GARCH \\
\hline 3.5 & 50 & 0 & 0 & 50 & 0.374046681 & 0.39727048 & 40 & GARCH \\
\hline 3.5 & 50 & 0 & 0 & 50 & 0.257348721 & 0.286997753 & 50 & GARCH \\
\hline 3.5 & 50 & 0 & 0 & 50 & 0.127600673 & 0.157490511 & 60 & GARCH \\
\hline 3.5 & 50 & 0 & 0 & 50 & 0.115796508 & 0.144950096 & 61 & GARCH \\
\hline 3.5 & 50 & 0 & 0 & 50 & 0.104467238 & 0.132703523 & 62 & GARCH \\
\hline 3.5 & 50 & 0 & 0 & 50 & 0.093646999 & 0.120804717 & 63 & GARCH \\
\hline 3.5 & 50 & 0 & 0 & 50 & 0.083403166 & 0.109320114 & 64 & GARCH \\
\hline 3.5 & 50 & 0 & 0 & 50 & 0.073761093 & 0.09830096 & 65 & GARCH \\
\hline
\end{tabular}

These two tables with their combined 40 depletion probabilities represents only $0.04 \%$ of the total dataset computed.

In general, the random walk model results have more dispersion than results from the ARIMA/GARCH model. One hypothesis for this phenomenon is that the random walk model permits successive extreme positive and negative events, which is generally precluded in the ARIMA/GARCH model. With ARIMA/GARCH, lightening tends not to strike twice in consecutive months.

Despite, the models are generally quite consistent and both recommend nearly the same portfolio mixes for the same input conditions and have reasonably close estimates when the likelihood of portfolio failure is low.

It is obvious from the portfolio survival/depletion Tables 7 and 8 that what constitutes a "safe" withdrawal rate depends upon one's definition of "safe". This, in turn, depends upon the retiree's risk tolerance. For analysis purposes, we propose the following investor risk tolerance categories;

- $\quad$ Aggressive: $p$ (portfolio depletion $\leq 0.20)$

- $\quad$ Moderate: $p($ portfolio depletion $\leq 0.10)$

- Conservative: $p$ (portfolio depletion $\leq 0.05$ )
- Very risk-adverse: $p$ (portfolio depletion $\leq 0.02)$

\section{DATA ANALYSES}

There are a number of conclusions one can draw from these modeling results which, though perhaps intuitively obvious, are not or rarely systematically analyzed in other studies.

First, the likelihood of portfolio depletion prior to mortality decreases with age. A 95-year-old man who wishes to retire can clearly withdraw more of his money each year than a 20 -yearold woman. A 20-year-old may have a 70-80 year lifespan to look at, and there may be some rather cataclysmic scenarios over that course of time, including runaway inflation, the longterm collapse of stock prices and/or the collapse of bond prices. Pegging withdrawals to inflation can be a real problem if inflation explodes and stocks collapse. The message for the young Financial Independence Retire Early (FIRE) retirees of today is that they need to be more conservative in their withdrawal strategies, not less.

The second point is that the amount that can be safely withdrawn depends upon sex and marital status. This also is seen in Tables 98 and 99. Women have longer expected lifespans than men, so it is to be expected that they would have a higher probability of outlasting their portfolio for a given withdrawal rate. This holds even more so for married couples.

The third point is that withdrawal rate can significantly affect the likelihood of portfolio collapse prior to mortality. Consider Tables 9 and 10:

Table 9: Random Walk, 50\% stock/treasury, Age 65

\begin{tabular}{|c|c|c|c|c|c|c|c|c|}
\hline Withdrawal rate & $\%$ T-Bonds & \% AAA Bonds & $\%$ BAA Bonds & $\%$ Stocks & Male & Female & Age & Model \\
\hline 1 & 50 & 0 & 0 & 50 & 0 & 0 & 65 & Random Walk \\
\hline 1.5 & 50 & 0 & 0 & 50 & 0 & 0 & 65 & Random Walk \\
\hline 2 & 50 & 0 & 0 & 50 & $6.61 \mathrm{E}-06$ & $1.71 \mathrm{E}-05$ & 65 & Random Walk \\
\hline 2.5 & 50 & 0 & 0 & 50 & 0.000746316 & 0.001537997 & 65 & Random Walk \\
\hline 3 & 50 & 0 & 0 & 50 & 0.008672734 & 0.015278151 & 65 & Random Walk \\
\hline 3.5 & 50 & 0 & 0 & 50 & 0.036079632 & 0.056910717 & 65 & Random Walk \\
\hline 4 & 50 & 0 & 0 & 50 & 0.090735529 & 0.132056051 & 65 & Random Walk \\
\hline 4.5 & 50 & 0 & 0 & 50 & 0.174624994 & 0.237169548 & 65 & Random Walk \\
\hline 5 & 50 & 0 & 0 & 50 & 0.276821366 & 0.35506925 & 65 & Random Walk \\
\hline 5.5 & 50 & 0 & 0 & 50 & 0.374334639 & 0.459533582 & 65 & Random Walk \\
\hline 6 & 50 & 0 & 0 & 50 & 0.470192825 & 0.555055992 & 65 & Random Walk \\
\hline
\end{tabular}

Table 10: ARIMA/GARCH, 50\% stock/treasury, Age 65

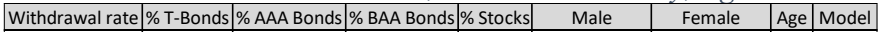

\begin{tabular}{|c|c|c|c|c|c|c|c|c|}
\hline 1 & 50 & 0 & 0 & 50 & 0.000172736 & 0.00027263 & 65 & GARCH \\
\hline 1.5 & 50 & 0 & 0 & 50 & 0.001356851 & 0.002057798 & 65 & GARCH \\
\hline 2 & 50 & 0 & 0 & 50 & 0.005072838 & 0.007431436 & 65 & GARCH \\
\hline 2.5 & 50 & 0 & 0 & 50 & 0.015174942 & 0.021864865 & 65 & GARCH \\
\hline 3 & 50 & 0 & 0 & 50 & 0.037339829 & 0.051464852 & 65 & GARCH \\
\hline 3.5 & 50 & 0 & 0 & 50 & 0.073761093 & 0.09830096 & 65 & GARCH \\
\hline 4 & 50 & 0 & 0 & 50 & 0.126665465 & 0.1633324 & 65 & GARCH \\
\hline 4.5 & 50 & 0 & 0 & 50 & 0.194364623 & 0.24273765 & 65 & GARCH \\
\hline 5 & 50 & 0 & 0 & 50 & 0.277000387 & 0.335129723 & 65 & GARCH \\
\hline 5.5 & 50 & 0 & 0 & 50 & 0.358554081 & 0.422428984 & 65 & GARCH \\
\hline 6 & 50 & 0 & 0 & 50 & 0.439391255 & 0.505635776 & 65 & GARCH \\
\hline
\end{tabular}

With both models, withdrawal rates of $2 \%$ for a 65 -year-old male or female have almost no chance of portfolio collapse, but a $6 \%$ withdrawal rate increases the likelihood to about $50 \%$ !

An interesting feature of both models is that the portfolio depletion probabilities are dependent upon the initial economic conditions. At the time of this writing (late 2021), interest rates are at historic lows and inflation is very high. As a direct result of this, both the Random Walk and ARIMA/GARCH models forecast that treasuries and bonds are not safe investments. This is because when bond yields are low and inflation is high, a portfolio invested in these assets is actually continuously losing real money due to the interest received not keeping up with 
inflation. This shortfall cannot be made up for in capital gains, either. With treasury yields already near zero (1.5\% for 10 -year US treasuries as of this writing) and a hard lower bound of $0.0 \%$ for future interest rates, potential future capital gains due to interest rate reductions are severely limited.

The riskiness of bonds and treasuries is strikingly illustrated in Table 11 below which shows that with the Random Walk model, investing in bonds or treasuries results in a very high likelihood of portfolio collapse, while investing in stocks is safe for both male and female 65 -year-old retirees.

Table 11: Random Walk, Single asset, 4.0\% Withdrawal

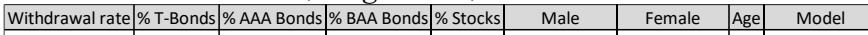

\begin{tabular}{|c|c|c|c|c|c|c|c|c|}
\hline 4 & 100 & 0 & 0 & 0 & 0.514527497 & 0.605973953 & 65 & GARCH \\
\hline 4 & 0 & 100 & 0 & 0 & 0.515415865 & 0.603979572 & 65 & GARCH \\
\hline 4 & 0 & 0 & 100 & 0 & 0.473118636 & 0.562174564 & 65 & GARCH \\
\hline 4 & 0 & 0 & 0 & 100 & 0.076223612 & 0.090004252 & 65 & GARCH \\
\hline
\end{tabular}

A note concerning the fact that the two models produce results which, though consistent, can differ slightly, especially when the likelihood of portfolio collapse is high. So, which one should one choose? That is a matter of personal preference. The Random Walk model makes no assumption about future direction, other than the markets walk randomly in a manner similar to have they have walked in the past. The ARIMA/ GARCH model assumes that there are long term trends in the data and its spread, and uses statistical analysis to pick out those trends. However, they are both only models.

Another approach that could be followed, common in data modeling circles, is to use an ensemble of models and average their results.

It is easy to see that there are large number of different "what if" scenarios that an individual investor or retirement planner can evaluate with this dataset. For example, one can choose the maximum safe withdrawal rate and optimal portfolio composition given a client's risk tolerance. On the other hand, if a client has a need for a certain amount of income, then the investment advisor can determine the portfolio that is most likely to achieve that income level with the least risk. As yet another example, an analyst can identify the optimum retirement age to match a prospective retiree's risk tolerance and income needs.

So, what is the best safe withdrawal rate? As noted throughout this paper, it depends upon a number of factors. But for a 65 -year-old male with moderate risk tolerance, using the ensemble model averaging technique and interpolating between data points, the safe withdrawal rate as of this writing is about $4.55 \%$ and the optimum portfolio consists of $95 \%$ stocks and $5 \%$ BAA-rated bonds. It is very important to understand that the safe withdrawal rate and optimum portfolio composition will change as market conditions change, and in particular that the optimum bond allocation will increase as interest rates increase and inflation decreases.

\section{CONCLUSION AND POTENTIAL FURTHER RESEARCH}

Every optimum withdrawal rate estimate for retirement relies upon econometric models or economic assumptions, either explicit or implicit.

This paper makes explicit the econometric modeling involved in performing these estimates, and as a result the portfolio survival probabilities were able to be quantified by sex, retirement age, portfolio composition and safe withdrawal rate. As this modeling shows, there is no single "safe withdrawal rate". The amount that can be safely withdrawn varies by all of these factors, as well as the retiree's risk tolerance.

There are a number of studies that can be performed that improve upon this work, including the addition of more models, improvement of the existing models, and selection of additional asset classes. There are also a number of extensions to this study that can be performed, including applying the methodology described in this paper to other countries and considering additional mortality factors such as health and income.

The data from this study can also be used to develop a tool that can assist retirement planners in discussing alternate strategies with their clients, tailoring the selected strategy for each client's unique situation.

\section{REFERENCES}

[1] Bengen, William, "Determining Withdrawal Rates Using Historical Data", Journal of Financial Planning. October, 1994: 171-180.

[2] Bengen, William, "Asset Allocation for a Lifetime", Bengen, William P. "Asset Allocation for a Lifetime." Journal of Financial Planning. August 1996: 58-67.

[3] Bengen, William, "Conserving Client Portfolios During Retirement, Part III." Journal of Financial Planning. December 1997: 84-97.

[4] Benz, Christine, Jeffrey Ptak and John Rekenthaler, "The State of Retirement Income Safe Withdrawal Rates". November 11, 2021. Retrieved from https://www.morningstar.com/lp/the-state-of-retirementincome.

[5] Finke, Michael, Wade D. Pfau, and David M. Blanchett. 2013. "The 4 Percent Rule Is Not Safe in a Low-Yield World.” Journal of Financial Planning 26 (6): 46-55.

[6] DeJong, Jack C., and John H. Robinson 2017. "Determinants of Retirement Portfolio Sustainability and Their Relative Impacts." Journal of Financial Planning 30 (4): 54-62.

[7] Rusoff, Jane Wollman. 2020. "Wade Pfau: Pandemic Tears up 4 Percent Rule.” Interview with Wade Pfau, April 14, 2020. https://www.thinkadvisor.com/2020/04/14/wade-pfau-virus-crisis-hasslashed-4-rule-nearly-in-half/

[8] Arends, Brett. "The inventor of the 4 percent rule just changed it". Market Watch, November 2020. Retrieved from https://www.marketwatch.com /story/the-inventor-of-the-4-rule-just-changed-it-11603380557

[9] Pfau, Wade. "An International Perspective on Safe Withdrawal Rates from Retirement Savings: The Demise of the 4 Percent Rule?", GRIPS Policy Research Center Discussion Paper: 10-12. September, 2010. Downloaded from http://www3.grips.ac.jp/ pinc/data/10-12.pdf

[10] Drew, Michael and Walk, Adam. "Just how safe are 'safe withdrawal rates' in retirement?". Financial Planning Research Journal, VOLUME 1. ISSUE 1 - 2015, pgs. 22-32

[11] Costa, Paulo, David Pakula and Andrew S. Clarke, "Fuel for the F.I.R.E.: Updating the 4\% rule for early retirees". Vanguard, 2021. Valley Forge, Pa. The Vanguard Group. Retrieved from https://personal.vanguard.com/ pdf/ISGFIRE.pdf.

[12] Estrada, Javier. "Managing to target (ii): Dynamic Adjustments for Retirement Strategies". Journal of Retirement, Volume 7, Number 4, Spring 2020: 28-38.

[13] Engle, R.F. Autoregressive conditional heteroskedasticity with estimates of the variance of U.K. Inflation. Economics 1982, 50, 987-1008.

[14] Nobel Prize Committee, "Robert F. Engle III Facts". 2003. Retrieved from https://www.nobelprize.org/prizes/economic-sciences/2003/engle/ facts/".

[15] Bollerslev, Tim. "Generalized Autoregressive Conditional Heteroskedasticity.” Journal of Econometrics 31 (1986) 307-327. 
[16] Shiller, Robert J. "Inflation and Stock Market Return Data". 2021. Retrieved from http://www.econ.yale.edu/ shiller/data.htm.

[17] Federal Reserve Bank of St. Louis, "Moody's Seasoned Aaa Corporate Bond Yield (AAA)". (2021). Retrieved from https://fred.stlouisfed.org/series/AAA.

[18] Federal Reserve Bank of St. Louis, "Moody's Seasoned Aaa Corporate Bond Yield (BAA)". (2021). Retrieved from https://fred.stlouisfed.org/series/BAA.

[19] European Central Bank, "USA 10-year Government Benchmark bond yield - Yield, average of observations through period." (2021). Retrieved from https://sdw.ecb.europa.eu/quickview.do?SERIES_KEY=143.FM. M .US.USD.4F.BB.US10YT_RR.YLDA.

[20] Cox, Jeff. "Powell says the Federal Reserve is not considering negative interest rates." CNBC, May 13, 2020. Retrieved from https://www.cnbc. com/2020/05/13/powell-says-the-federal-reserve-is-not-looking-atnegative-interest-rates.html.

[21] Pension Benefit Guarantee Corporation. "ERISA Section 4044 Mortality Table for 2021 Valuation Dates." Rerieved from https://www.pbgc.gov/prac/mortality-retirement-and-pv-max-

guarantee/erisa-mortality-tables/erisa-section-4044-mortality-table-for2021-valuation-dates 